\title{
How Do I matter? A Review of the Participatory Design Practice with Less Privileged Participants
}

\author{
María Laura Ramírez Galleguillos \\ Koç University Arçelik Research Center for Creative \\ Industries, Koç University, İstabul, Turkey \\ mgalleguillos18@ku.edu.tr
}

\author{
Aykut Coşkun \\ Koç University Arçelik Research Center for Creative \\ Industries, Koç University, İstabul, Turkey \\ aykutcoskun@ku.edu.tr
}

\begin{abstract}
In participatory design, different methods are applied to build individuals' participation and engagement in design processes. Nonetheless, some less privileged participants can face more barriers to participation than others, e.g., being unable to exercise their voice. The literature lacks a unified source that guides PD researchers and practitioners in devising and implementing projects with groups facing more barriers to participation. This paper addresses this gap and advances the field in two ways. First, by presenting an assessment of the current state of the art through a review of 46 participatory projects that involved less privileged participants, it identifies the diversity of participants involved in these projects, and the methods and the stage of their involvement. It also frames three conceptualizations of PD and presents common challenges researchers and participants faced during these projects. Second, based on this analysis, it presents areas for further development and discusses the implications for PD.
\end{abstract}

\section{CCS CONCEPTS}

- Human-centered computing $\rightarrow$ Interaction design.

\section{KEYWORDS}

PD practice, Less-Privileged, Undermined, Participant's Involvement, Literature Review

\section{ACM Reference Format:}

María Laura Ramírez Galleguillos and Aykut Coşkun. 2020. How Do I matter? A Review of the Participatory Design Practice with Less Privileged Participants. In Proceedings of the 16th Participatory Design Conference 2020 - Participation(s) Otherwise - Vol 1 (PDC '20: Vol. 1), fune 15-20, 2020, Manizales, Colombia. ACM, New York, NY, USA, 11 pages. https://doi.org/10.1145/3385010.3385018

\section{INTRODUCTION}

Participatory design (PD) proposes that the people who will be influenced by a new design or a technology should have a saying in its development [5]. From its origins, with the Scandinavian co-design movement, PD was related to workers and different stakeholder's involvement in the design process, trying to co-determinate ways

Permission to make digital or hard copies of all or part of this work for personal or classroom use is granted without fee provided that copies are not made or distributed for profit or commercial advantage and that copies bear this notice and the full citation on the first page. Copyrights for components of this work owned by others than the author(s) must be honored. Abstracting with credit is permitted. To copy otherwise, or republish, to post on servers or to redistribute to lists, requires prior specific permission and/or a fee. Request permissions from permissions@acm.org.

PDC '20: Vol. 1, June 15-20, 2020, Manizales, Colombia

(C) 2020 Copyright held by the owner/author(s). Publication rights licensed to ACM ACM ISBN 978-1-4503-7700-3/20/06 _\$15.00

https://doi.org/10.1145/3385010.3385018 to operate information systems $[19,45,68]$. Since then, PD has evolved in various ways. Today it is more related to including people in design projects to envision the use of technology before its actual use $[7,60]$ and to promote participants' empowerment [13]. Different methods are applied to achieve these goals, shaping the influence participants have on the design process and decision making $[68,76]$. Investigating these methods has become a critical aspect of $\mathrm{PD}$ research and practice.

Despite the range of methods available to designers and researchers, there have been various concerns about how participation is framed by PD [10, 21, 45]. These include how participation is constructed (i.e., how participants influence decision-making) [59], whether it is possible to endure the values of PD in practice [76], and the unspoken assumptions behind the selection of a specific research method $[23,45,54]$. Other concerns were about the meaning and understanding of participation. For instance, Carroll stated that "participation" was losing its meaning in HCI [41]. Vines et al. [76] urged the PD community to work on mapping the definitions and best practices of participation. Arguing that the selection of a particular method frames the influence of participants in the design projects, Halskov and Hansen [36] proposed that we should question where, when, and how the participants are included in the design process. Finally, there have been concerns about how the methods distribute decision-making [45] and address social, cultural, and power relationships [54,63].

Even though these concerns are relevant for most PD projects, they become even more critical when working with often unprivileged participants. These include, for example, people who have been excluded or experienced disadvantages due to not having access to material resources, being unable to exercise their voice, or being discriminated in the basis of their age, sex, disability, race, ethnicity, or economic and migration status [24, 25]. Also, according to the UN, experiencing these disadvantages can make these people feel less powerful, less confident, and less likely to succeed, and in so, less likely to exercise participation [24]. That is to say, the bigger the social, cultural, and power-relationship gap stemmed from these disadvantages, the more barriers and challenges exist for the participation of less privileged participants.

PD researchers and practitioners can face various challenges when devising and implementing PD projects with less privileged participants. However, the literature lacks an integrative source that can help them overcome these challenges. This study addresses this gap and advances the field in two aspects. First, it presents an assessment of the current state of the art by reviewing 46 participatory design projects. This review identifies the diversity of participants involved in these projects, the methods applied to engage participants, 
the design stage they were involved in, the researcher's conceptualization of $\mathrm{PD}$, and common challenges faced by researchers and participants. Second, based on the mentioned analysis, it discusses the implications of these findings for participatory design along with areas that need further development.

\section{THE STUDY}

In this study, more than having a theoretical approach, we focused on understanding the methods applied in PD projects, as these practices frame the ways for a participant to influence a design project [36]. Our aim was to understand how participation is being built when participants have experienced less privileges, which creates more barriers for them to exercise their participation. Moreover, through this understanding, we believed we could extract lessons, and make suggestions to improve the current and future practices of PD. Our driving question was, "How is participation unpacked when working with participants who encounter additional barriers to participation". Thus, we conducted a literature review of participatory design processes that involved participants perceived as unprivileged and disadvantaged, as stated by the individual authors. We note that we did not define which participants were identified as "less-privileged" beforehand, this point was as a result of the keywords search.

\subsection{Reviewed sources}

We determined the reviewed sources in three stages. First, we identified the search keywords, that we arranged several times throughout the search. The keywords were participatory design, unprivileged communities, minorities, undermined communities. We started the search with the Participatory Design Conference since it has been the main venue for disseminating PD work since 1990. We found 174 papers. Then, we searched the International fournal of CoCreation in Design and the Arts as it is a journal that publishes studies specializing in co-creation and collaborative design since 2005. We found 23 articles. We expanded this list with a search on Google Scholar. We found 107 papers. After sorting out the duplicate papers in these databases and applying the inclusion/exclusion criteria, we finally had a corpus of 46 articles.

2.1.1 Inclusion/exclusion criteria. We set several criteria to select the most relevant papers from the corpus. The first was the paper's relation to $\mathrm{PD}$ and the involvement of participants that might face less privileges. We conducted a preliminary analysis looking to what extent the papers referred to PD, this meant whether the paper presented a participatory design process or PD was included as related work. We excluded papers belonging to the latter category. Also, there were instances where the studies described a PD process but, their participants were not part of our target group, i.e. participants experiencing more barriers to participation due to exclusion, having less privileges or advantages. The second criterion was the type of publication. We only selected full papers at conferences or journal articles that explained an applied participatory design process. Thus, we excluded Ph.D. theses, reports, theoretical papers, and books from the analysis. The third criterion was the time. We only selected research conducted during the past ten years. We aimed to assess the state of the most current PD research and practice. With the criteria above, we selected 46 papers (11 from PDC, 10 from Co-design Journal and 25 from Google Scholar).

\subsection{Method of analysis}

We conducted the review in three stages, using thematic analysis for coding [14]. The first stage was an overall annotated reading of the sources. In the second stage, we analyzed and categorized the papers according to four dimensions:

i) the participants involved in these projects,

ii) the methods used to engage them,

iii) the design stage where the involvement occurs, and

iv) the conceptualization of participation. In the third stage, we analyzed the papers according to the challenges faced by researchers and participants throughout the process and the good practices that illustrate how these challenges can be overcome.

\section{FINDINGS}

In this section, we present the results of the analysis of the dimensions mentioned above: participants, methods, stages, conceptualization, challenges and good practices (Table 1).

\subsection{Involved Participants}

In a first analysis, we approached this topic as communities (i.e. people living in one particular area or people who are considered as a unit because of their common interests, social group, or nationality[20]) but by studying the research we understood that the people involved on the projects were individual participants and we could not approach them as a community, uniting them just in the base of a common need. For this reason, we refer to them as participants involved. We identified eight different groups of participants perceived as individuals with less privileges by the reviewed papers. In this section, we present these groups. We note that however, we do not aim to frame the various participants in these groups as homogenous in their needs and characteristics. Rather, our aim was to identify tendencies among the reviewed studies in terms of participant selection.

The first participant group was children (n:15), referring to individuals under 15 years old. Inside this group, there were studies working with children with autism [31, 58, 64], children at risk of marginalization $[2,32]$, and children that require prosthetics legs $[38,39]$. The rest of these studies referred to their participants as children [6, 26, 27, 40, 46, 55, 78, 83]. The second group was refugees, immigrants and, asylum seekers (n:8). These works included participants resettled in Australia [1, 15] Sweden [22], Germany [29], overall Europe [55], Canada [66] and Urban refugees in Rwanda [84]. The third group was people with cognitive or physical impairments (n:7). This group included people in need of mental help $[8,44,57,77]$, adults with diabetes [42], dementia [11] and aphasia [33]. The fourth group was older adults (n:6), people over 60 years old, who have special needs regarding city planning [35] and digital technologies [37, 48, 49, 55, 75]. The fifth group was ethnic and aboriginal tribes (n:6). This group was composed of tribes located in Australia [51, 70], Namibia [17, 81, 82] and one ethnic community located in China [80]. The sixth group was individuals in critical neighborhoods (n:6), who participated in projects promoting 
resilience and social cohesion $[30,66,69,72]$, health [43] and community reflection [47]. It is relevant to highlight that these projects involved different communities as, for example, children and older adults at the same time. The seventh group was women (n:3), who were involved in projects related to the gender gap $[16,55]$ and wellbeing [55]. Finally, there were works related to unemployed people (n:2), who faced barriers in their search for a job $[55,73]$.

Most of these studies (n: 41/46) focused on creating solutions or empowering interventions for one specific participant group. But, as it happened in the case of critical neighborhoods, some studies involved more than one group (e.g., older adults, children, immigrants) who worked together in the design process. Besides, 33 of the selected studies included other stakeholders (e.g., parents, teachers, municipalities, friends) in the research process, who participated mostly in framing the research or problem or as a consultant during the design process.

\subsection{Stage of involvement}

We observed different patterns concerning the stage of the participant's involvement in the design process (Table 2). In other words, different participant groups influence projects at different moments.

Mostly all the studies (n:43) include the participants in problem framing, trying to understand the needs the participants have. Almost the same number of projects (n:44) involve the participants in ideation activities, seeking to promote creativity skills and envisioning activities [12]. The third stage with more participation is validation (n:38) on which participants are involved in different kinds of testing activities from giving feedback about a design to usability testing. When it comes to building activities, referring to developing prototypes of different resolutions, we found less studies (n:12) that involve the participants on this stage. So, the norm is that designers define the problem with participants, then develop ideation activities with them, they take this information to build prototypes that are then, presented to the participants to get feedback.

In that sense, we didn't find many studies that reported having included the participants in the complete process, as there were very few cases where the participants were involved in building and validation stages at the same time. One of those examples is the work developed in critical neighborhoods. In this case, it was very common that the problem was already framed by a stakeholder (e.g., municipalities), and that participants got involved in ideation, building (i.e., codesign and prototyping sessions) and validation. Another case that was distinguishable from the aforementioned ones are the studies conducted with children with autism. When working with children with autism we found that they were not directly involved in problem-framing, instead, they tended to participate in ideation and validation activities. In such studies, problem framing was done with other stakeholders such as clinicians, teachers, and parents while building stage was developed by designers.

\subsection{Method of involvement}

In this section, we present the most common methods of involvement in our corpus. Methods are selected concerning the stage where participants are involved and the particular characteristics of the participants. We will explain how these two factors influence the method selection. From the most common to the least common, these methods are workshops, interviews, naturalistic observations, and toolkits.

3.3.1 Workshops. In our analysis, we considered all group gatherings that involved participants discussing a topic or conducting hands-on activities as workshops. This technique was used with all the participant groups we identified because it gives the possibility of working with more people at the same time. We observe that researchers select the workshops in relation to their aim, that can include understanding the needs and behaviors of participants [47, 48, 69], ideating together [22, 27, 47, 77], getting feedback about an idea [31,77], learning together [84], engaging in scenario-based discussions and envisioning activities [49, 57, 58].

Furthermore, researchers also tailor the workshops to participants' characteristics by selecting specific activities. Because workshops implicate interacting with others, some participants can feel less comfortable and less open to talking about personal issues. In this respect, we observed that researchers try to promote a more relaxed environment. For instance, workshops with children tend to be more playful, putting efforts into making children feel comfortable and engaged in the activities, besides opening their imagination $[40,79]$. It is very common to use games and videos in these workshops, e.g. children playing imaginary instruments to help children imagine how this musical instrument could be [32]. In the case of people in need of mental help $[8,57,77]$, it was common to use envisioning and scenario-based activities, such as persona immersion $[9,74]$. These types of activities gave them the opportunity of projecting personal issues in the imaginary persona they were building, reducing the pressure to be vulnerable about their struggles. In the case of older adults, tea parties [75] were conducted that were more of an informal kind of talk, which allowed them to feel more comfortable during discussions and developing activities, as it gives the feeling of a meeting with friends. Along with the latter, with older adults, envisioning activities as the invisible design concept were applied to help them think beyond constraints [49]. Besides tailoring the activities, the structure of the workshops can be adapted to new needs identified while conducting the workshops. For example, with older adults participating in the development of ICT [37] the authors mentioned that after six months they realized the participants needed support with technology, so they decided to divide the former workshop into two parts, one supporting technology appropriation and the other focusing on the design of a portal.

A different kind of workshops were the activities that promoted the participant's empowerment and learning. The latter aimed at transferring skills to the participants in different formats. For example, in the case of refugees, immigrants and asylum seekers, some studies worked on providing training for them to collect information by themselves and contribute as a research partner [81, 84], this also occurred with older adults to be engaged with technology [37]. The former allowed them to feel more connected and involved in the projects, besides giving a sense of the importance of their participation.

3.3.2 Interviews. Interviews consisted of structured one-on-one dialogs with participants. These were commonly applied in the early stages of the design process (problem framing), with the intention of 
Table 1: Summary of the participants involved, design outcomes, topics, research methods and stage of involvement

\begin{tabular}{|c|c|c|c|c|c|}
\hline Groups & Studies & $\begin{array}{l}\text { Design } \\
\text { outcomes }\end{array}$ & Common topics & Research methods & $\begin{array}{l}\text { Stage of } \\
\text { involvement }\end{array}$ \\
\hline CHILDREN & $\begin{array}{l}15 \\
{[2,6,55,58,} \\
64,79,83,26, \\
27,31,32,38, \\
40,46]\end{array}$ & $\begin{array}{l}\text { CVE, Learning } \\
\text { Environment, } \\
\text { VR, Education } \\
\text { technologies } \\
\text { Musical } \\
\text { instruments } \\
\text { Digital } \\
\text { technologies } \\
\text { Spatial design } \\
\text { Prosthetic legs } \\
\text { Parks } \\
\text { Arts Center }\end{array}$ & $\begin{array}{l}\text { Social skills } \\
\text { Communication } \\
\text { Children-friendly } \\
\text { cities } \\
\text { Reading skills } \\
\text { Empowerment } \\
\text { Development }\end{array}$ & $\begin{array}{l}\text { Interviews: questionnaires, } \\
\text { wish-list } \\
\text { Observations: cultural probes, field } \\
\text { trips } \\
\text { Workshops: Paper prototyping, } \\
\text { roleplaying, bags of stuff, videos, } \\
\text { games (dessert island, odd-one-out, } \\
\text { VR games, comic's drawing, } \\
\text { obscured theatre, the mission from } \\
\text { mars, designing for Mr. hypo) } \\
\text { Toolkits: toolbox, kid reporter }\end{array}$ & $\begin{array}{l}\text { Problem } \\
\text { framing } \\
\text { Ideation } \\
\text { Validation }\end{array}$ \\
\hline $\begin{array}{l}\text { REFUGEES, } \\
\text { IMMIGRANTS AND } \\
\text { ASYLUM SEEKERS }\end{array}$ & $\begin{array}{l}8 \\
{[1,15,22,29} \\
55,66,84]\end{array}$ & $\begin{array}{l}\text { Housing } \\
\text { E-services } \\
\text { Expression } \\
\text { media }\end{array}$ & $\begin{array}{l}\text { Data collection } \\
\text { Social cohesion } \\
\text { Social inclusion } \\
\text { Post-traumatic } \\
\text { experiences }\end{array}$ & $\begin{array}{l}\text { Interviews: interviews with props } \\
\text { Observation: Cultural immersion } \\
\text { Workshops: open discussions, } \\
\text { videos } \\
\text { Toolkits: cultural probes } \\
\text { *participation in data collection }\end{array}$ & $\begin{array}{l}\text { Problem } \\
\text { framing } \\
\text { Ideation } \\
\text { Validation }\end{array}$ \\
\hline OLDER ADULTS & $\begin{array}{l}6 \\
{[35,37,48,49,} \\
55,75]\end{array}$ & $\begin{array}{l}\text { E-systems } \\
\text { Community } \\
\text { gardens } \\
\text { Knowledge }\end{array}$ & $\begin{array}{l}\text { Social cohesion } \\
\text { Technology } \\
\text { appropriation }\end{array}$ & $\begin{array}{l}\text { Interviews } \\
\text { Observation } \\
\text { Workshops: Paper prototyping, } \\
\text { focus groups, tea parties, games, } \\
\text { scenario-based discussions, visions } \\
\text { creation, digital storytelling }\end{array}$ & $\begin{array}{l}\text { Problem } \\
\text { framing } \\
\text { Ideation } \\
\text { Building }\end{array}$ \\
\hline $\begin{array}{l}\text { PEOPLE WITH } \\
\text { COGNITIVE OR } \\
\text { PHYSICAL } \\
\text { IMPAIRMENTS }\end{array}$ & $\begin{array}{l}7 \\
{[8,11,33,42} \\
44,57,77]\end{array}$ & E systems & Wellbeing & $\begin{array}{l}\text { Interviews } \\
\text { Workshops: Persona immersion, } \\
\text { mapping, sketches, scenario-based } \\
\text { discussion, 3D mock-ups }\end{array}$ & $\begin{array}{l}\text { Problem } \\
\text { framing } \\
\text { ideation, } \\
\text { Validation }\end{array}$ \\
\hline $\begin{array}{l}\text { ETHNIC AND } \\
\text { ABORIGINAL }\end{array}$ & $\begin{array}{l}6 \\
{[17,51,70,} \\
80-82]\end{array}$ & $\begin{array}{l}\text { Musical } \\
\text { instruments } \\
\text { E-Systems }\end{array}$ & $\begin{array}{l}\text { Artistic expression } \\
\text { Social cohesion }\end{array}$ & $\begin{array}{l}\text { Observation: cultural immersion, } \\
\text { informal meetings } \\
\text { Workshops: Focus groups, cultural } \\
\text { immersion, rapid prototyping, } \\
\text { digital prototyping, videos } \\
\text { Interviews } \\
\text { Toolkits: cultural probes }\end{array}$ & $\begin{array}{l}\text { Problem } \\
\text { framing } \\
\text { Ideation } \\
\text { Validation }\end{array}$ \\
\hline $\begin{array}{l}\text { CRITICAL } \\
\text { NEIGHBORHOODS }\end{array}$ & $\begin{array}{l}6 \\
{[30,43,47,66,} \\
69,72]\end{array}$ & $\begin{array}{l}\text { Community } \\
\text { projects } \\
\text { Garden beds } \\
\text { Tools for } \\
\text { reflection Films } \\
\text { E-services } \\
\text { Housing }\end{array}$ & $\begin{array}{l}\text { Community } \\
\text { engagement Social } \\
\text { cohesion Social } \\
\text { inclusion } \\
\text { Discrimination }\end{array}$ & $\begin{array}{l}\text { Interviews } \\
\text { Observations: informal talks, field } \\
\text { notes, field trips, participatory } \\
\text { walks } \\
\text { Workshops: drawings, maps, open } \\
\text { discussions, focus groups, } \\
\text { scenario-based activities, video } \\
\text { making, prototyping, space } \\
\text { mock-ups, games, } \\
\text { *participation in data collection }\end{array}$ & $\begin{array}{l}\text { Problem } \\
\text { framing } \\
\text { Ideation } \\
\text { Building } \\
\text { Validation }\end{array}$ \\
\hline WOMEN & $\begin{array}{l}3 \\
{[16,51,55]}\end{array}$ & $\begin{array}{l}\text { Knowledge } \\
\text { E-systems }\end{array}$ & $\begin{array}{l}\text { Gender stereotypes } \\
\text { Social inclusion }\end{array}$ & $\begin{array}{l}\text { Workshops: Focus groups, } \\
\text { scenario-based discussions, } \\
\text { roleplaying, paper prototyping } \\
\text { Toolkit: cultural probes }\end{array}$ & $\begin{array}{l}\text { Problem } \\
\text { framing } \\
\text { Ideation }\end{array}$ \\
\hline UNEMPLOYED & $\begin{array}{l}2 \\
{[55,73]}\end{array}$ & E- system & Discrimination & $\begin{array}{l}\text { Interviews } \\
\text { Workshops: focus groups }\end{array}$ & $\begin{array}{l}\text { Problem } \\
\text { framing }\end{array}$ \\
\hline
\end{tabular}


understanding participants' needs and experiences. Interviews were also used in validation stages, focusing on participants' experience and interaction with the design output. Finally, they were also used to complement the information gathered by other methods as, for example, toolkits.

Although interviews are a typical method for ethnographic and qualitative research, it presents its own difficulties when applying it with participants experiencing less privileges. For example, as different studies showed, some participants can feel less prone to openly talk about their experiences or there might be a mistrust from previous participation in projects (i.e., not getting any benefit, not feeling understood). In this respect, researchers adapted the way they conduct the interviews to different characteristics of the participants. For example, in the case of children, interviews tend to be more playful $[38,39]$, whereas in the case of older people these were in a conversation-like format [35,37]. In the case of refugees, immigrants, and asylum seekers who might present some language barriers, wish-lists and questionnaires were used to simplify the communication process [64]. Furthermore, there was the flexibility to conduct these interviews on places that were more familiar for the participants, where they could feel more comfortable. An example of this is the work developed by Hussain [38, 39] working with children that needed prosthetic legs in Cambodia. In order to make them feel more relaxed when interviewing them, she conducted interviews and an important part of the research work in their houses, even when this represented a bigger investment of her time.

Finally, we observed that stakeholders were involved in interviews at any stage of the design process. The latter was a common practice when expert counseling is needed [6, 30, 69]. For example, researchers interviewed clinicians, teachers, and parents when working with children with autism $[58,64]$ to understand aspects related to their condition.

3.3.3 Observations. Observations are commonly conducted through field trips, where the researcher observes the behavior of the involved participants. In our corpus, there were two types of observations used: participant and non-participant observation. Usually, these kinds of observations are named concerning the participation of the researcher in the place of the observation. In addition to this point, we noticed that these observations also relate to the participation of the involved participants in the design project. In participant observation, the participants have the opportunity of deciding and explaining what it is presented to the researcher $[43,47]$ (e.g., a tribe showing how they make decisions) Whereas, with non-participant observation, they do not get to decide nor explain what is happening (e.g. children playing). Thus, in non-participant observations, field notes are mostly interpreted from the point of view and culture of the researcher without necessarily taking into consideration the background differences.

When working in a culturally different place, researchers conducted a different kind of observation through cultural immersion [80] (i.e., previous visits to understand cultural differences) by this, researchers developed their understanding of what people do, how they do it and the meanings behind some activities from the participants' perspective [4]. By conducting contextual observations, researchers understand needs, behaviors, attitudes, and practices, besides allowing the participants to feel more at ease with the researchers $[31,83]$. For the latter, cultural immersions represent an advantageous way of bonding and promoting understanding between researchers and participants.

3.3.4Toolkits. Toolkits are a set of instruments handled together with the specific aim of building a thing or guiding personal observations about a topic. These tools can be included as a part of a workshop or as a self-observation activity through generative tools $[67,71]$ and cultural probes $[3,78]$. The aim of these toolkits can vary. When used during a workshop, toolkits are more related to ideation and co-creation activities, where many different materials are used for prototyping a product or service. For example, toolbox [58] or bags-of-stuff [79] were kits that researchers handled different materials and tools like sticky notes, papers, pens, scissors, between others. When used outside the context of a workshop, toolkits are more related to self-observation activities. For example, cultural probes were a common method when working with children [39], refugees, immigrants and asylum seekers [1, 15], ethnic and aboriginal communities [82] and women [16] to guide them in the process of noticing their behaviors, feelings, and thoughts.

Similar to workshops and interviews, toolkits are adapted to the characteristics of different participants to match their skills and knowledge. For example, while toolkits were composed of drawings, games and specific daily questions to keep children focused $[31,39,52]$, in the case of older adults, toolkits included daily journals and photo-elicitation books [29,47]. Furthermore, toolkits tend to be complemented with a follow-up interview to clarify the meanings derived from the information provided by the toolkits. For example, researchers used follow-up interviews to better understand children's drawings as they can be difficult to analyze without further information [31, 39].

\subsection{Conceptualization of Participatory Design}

We found different conceptualizations of PD in the reviewed projects, that are based on the researcher's interpretation of what participation means. These conceptualizations were not explicitly stated by researchers since most of the studies introduce participatory design in a generic way (e.g., people influencing the projects that will affect them). Thus, the framing we developed was constructed based on the activities and opportunities given to the participants to influence the project. By studying the sources, we unpacked three conceptualizations to Participatory Design as practiced, these were: $P D$ as involvement in design activities, $P D$ as skill development and, PD as shared responsibilities. Likewise, we found six different roles the participants can play during participatory design projects, that are framed by these conceptualizations of PD.

3.4.1 PD as involvement in design activities. Looking across the studies in our corpus, participation as involvement in design activities is the most common approach to participation (n: 34$)$. With this approach, the participants can be involved in different stages of the design process by joining different design activities. These could be interviews, co-creation and idea generation workshops, and design validation. This is a very broad conceptualization of $P D$, and it assumes that by attending to design activities then participants influence the project. Depending on the type of activity and the 
stages of the involvement, participants can take three different roles when this approach is preferred:

Participants as informants: In 15 studies, participants have the role of the informant. In this case, participants get engaged in earlystage design activities such as information gathering, or observations for problem definition. Informants do not necessarily participate in further activities; however, they can be included in feedback or validation sessions, informing the final stages of the design process. In this respect, common activities they are included in, are interviews and focus groups, to collect information and insights about their needs. One example of this is the work conducted with unemployed people in Istanbul [73], where they participated in interviews about their process of looking for a job, the difficulties they face and then, participated in validating the solution developed.

Participants as partaker: in 12 studies, participants hold the role of the partaker. With this role, participants attend design activities of three different stages of the design process: problem framing, ideation, and validation. Diverging from informants, partakers participate in two extra stages (i.e., ideation and validation), which are generally developed in co-creation workshops. One example of the latter is the web platform developed for youth in need of mental help [77], a project initially developed with the participation of "mental health clients" and also clinicians. Then designers built it and took feedback from the clients in order to improve it.

Participants as validators: in 7 studies, participants have the role of the validator. In this case, they are engaged in the validation stages of the design process by testing ideas and giving feedback. It is essential to notice that, with this role, the design outcome has already been developed by previous participants or stakeholders. In this sense, what validators do is to test and give feedback about an already existing or developed design project. The difference with the previously introduced roles is the stage of the design process they get involved in (validation). The latter also tends to define what methods to use, for example, in validation stages participants tend to take part in usability testing instead of codesigning workshops (i.e., ideation stage). One example of the latter is the VR environment developed with children with autism [58]. In this work, we observe that most of the work of ideation and prototyping is developed with experts and professional and the participants were involved in validation and feedback stages.

By analyzing the studies that ponder Participatory Design as involvement in design activities, it is usually not clear to what extent the engagement on these activities (providing information, needs, ideas) will influence the final design outcome.

3.4.2 PD as skill development. Several studies (n: 6) promote skills development as the first step towards participation. As has been said, participants with less privileges can face more barriers to participation; for example, previous experiences being excluded, disadvantages due to not having access to material resources, not being used to exercise their voice or lack of literacy on a specific topic. Thus, working on the development of some skills for involvement is very relevant. For example, developing technological skills with older people is the first step for them to engage with digital technologies and use e-services [37], or train the participants with film making skills [66] is the first step for them to create their own films about the diversity and migration stories of their neighborhood.
Participants as learners: in 6 studies, participants have the role of learner. This conceptualization of PD understands that, in order to participate, people need not only the opportunity to participate, but capabilities, sense of agency, and literacy on the topics they will work on. Thus, it gives participants focuses on developing the participant's skills to increase their ability to participate. Learners can be present in different stages of the design process depending on the skills they need to develop.

3.4.3 PD as a shared responsibility. In some studies (n:6), participation is understood as a process where all the involved individuals (i.e., participants, stakeholders, and designers) should have an equal influence upon the process. This can be observed in activities that promote participants learning about each other, sharing power in decision-making, and co-perform research activities. In other words, with this approach, designers become participants as well. An example of this is the work developed by WinschiersTheophilus, Bidwell, and Blake with southern ethnic communities in rural Africa [81], wherein they performed activities to be included in the rural community. On that study, before developing a design intervention, the researchers went through a cultural immersion to understand the culture of the community and their ways of doing. When researchers understand participation as a shared responsibility, participants can take two different roles:

Participants as research partners: In three studies, the participants were involved in the PD process by being part of the data collection and research activities. In this regard, research is made with them and not only about them. By being a research partner, participants get to develop skills about the selected research method, apply it, and being part of the analysis influencing decision making about what to design. For example, in Xu \& Maitland [84], they propose participatory data collection as a way to "give voice to the studied population by allowing them to determine which data are important to solving their own problems".

Participants as design partners: in three studies, the participants take the role of design partners. They are not only involved in all stages of the design process but also in decision making about what it is going to be developed and how. That is to say, they also have a saying in terms of the activities, tools and methods applied. Thus, they participate in the design of the participatory process. One example is Kanstrup and Bertelsen's [44] research where they explain how the activities are adapted to the participant's needs (i.e., people at risk of or with ill health) and suggestions. For example, the participants suggested to conduct the physical exercise activities in a gym, with music and more action than talking, they even requested for more social activities than just serious reflections, to which researcher's agreed.

\subsection{Challenges and good practices}

By conducting this review, we found difficulties that researchers and participants face when working together that can hinder participation. These are related to understanding each other, individual agency and power relations. We also found ways of overcoming these challenges, for example having a flexible process and adapting to participant's characteristics. In this section, we will elaborate on those findings. 
Table 2: Relation between roles and design stages.

\begin{tabular}{llcccc}
\hline Roles & $\begin{array}{l}\text { Project } \\
\text { framing }\end{array}$ & Problem framing & Ideation & Build & Validation \\
\cline { 2 - 3 } $\begin{array}{l}\text { Informant } \\
\text { Partakers }\end{array}$ & & & & \\
Validators & $*$ & $*$ & \\
Learner & & & \\
Research partner & & & \\
Design \\
partner
\end{tabular}

3.5.1 Understanding in participation. We found that a big challenge when working with participants that have experienced less privileges is the construction of a shared understanding. This concept relates to how people with different life experiences can understand other's ideas, beliefs, and personal meanings. In a participatory process, this understanding should be formed, negotiated and shared by the participants and researchers $[50,56]$. Further, it is needed to promote relationships and open communication in the participatory project, which will sustain the project in time [18, 28, 53]. In this sense, there is a need to build and promote understanding [65], between designers and participants and, among participants.

Misunderstanding can hinder participation because it can make it difficult to analyze the information gathered or because participants might not understand what is expected from them. This was a difficulty faced, for example, when designing with people with aphasia who had difficulties production and comprehension of textual and verbal language [33]. This challenge was facilitated by using gradual and clear verbal communication as well as using non-abstract images, which made it less confusing for participants and researchers to understand each other. Also, we found that cultural immersions were useful to prevent misunderstandings, as it happened in the case where researchers set themselves to understand the participants from the Herero tribe in Namibia as a first step to develop their project [81]. The latter can also be done by integrating to the team one person that knows the participants and is trusted by them [82] as this person can act as a mediator between participants and researchers. Also, informal talks were used for the researchers to learn from the participants $[43,75]$, as in the case of developing technologies with adults over 80 . In a sense, with these kinds of activities researchers try to understand and then adapt to participants' capabilities, having a more flexible approach.

3.5.2 Leveraging participation. When individuals have faced less privileges, marginalization (i.e., being mistreated, not being used to exercise their voice), or lack of resources, their agency can be constrained [24]. Thus, less privileged participants can feel less competent or insecure to be engaged in activities that might expose them or their vulnerabilities. The latter can promote unequal power relations between participants, making the already existing power gap bigger.

We found that to overcome this challenge, researchers promote activities where participants can perceive their contribution/importance to the project, i.e. how an individual's participation will influence the project and inform the design outcome. Examples of the latter are the cases that promote participants involvement in data collection activities $[30,84]$, where they can promote the topics that are relevant for them to include in the project, and skills development $[37,66]$ on which, by the end of the process participants can perceive the improvement or learning of a skill, as it happened in the case of the films developed in a neighborhood by the community to tell their stories of migration. Along with the latter, activities, whereby participants can openly talk without feeling so vulnerable, are a good way to overcome this challenge. For example, through projective techniques participants can talk about the feelings of a fictive character, instead of directly talking about themselves. When developing technologies with youth in need of mental support [8] the participants used persona immersion to create a Facebook page for the presented persona and then the journey map of this persona while looking for mental help. By this activity, participants do not need to relive previous difficult experiences for themselves.

3.5.3 Maintaining participation. We found that in many studies maintaining the participation of people in time represents a challenge. The latter is exposed by some projects starting with a group of participants and losing some on the way or having moments with more attendance to activities that others. For example in the work developed with older adults to preserve and augment the paper cheque as a means of making electronic payments [75] they mention having 16 participants, conducting 12 workshops on which participants attended at most 2, besides having a maximum attendance to workshops of 6 people. Another example is the involvement of older adults in the development of ICT [37], a project that lasted 36 months, conducting more than 70 workshops, they mentioned having 15 participants from where there were 5 more active.

In terms of time, the $\mathrm{PD}$ process presents some constraints, as these tend to be long processes. The latter puts some pressure around the methods that can be applied. For example, conducting a workshop involves organizing different people's schedules besides maintaining the participants interested in the activities so they continue to invest their time on the project. This goal is approached, from researchers perspective, by having flexibility related to schedules [37], by being open to suggestions of the participants about how to make the activities entertaining and engaging for them [44] and, sometimes, being flexible in terms of the place of the workshop $[39,42]$. 


\section{DISCUSSION}

In this study, we aimed at understanding how PD is developed and practiced when working with less privileged participants. We reviewed $46 \mathrm{PD}$ projects and examined the methods used for involving participants, since these methods frame the ways participants can influence a design project [36]. In this section, we present the implications of our analysis along with areas that require further attention from our community. We grouped these implications into three broad themes: Transparency and open communication, Reframing participants' roles towards higher levels of involvement and, Evaluating the long-term impact of participation.

\subsection{Transparency and open communication}

The sources in our corpus have different levels of ambiguity about their project's process. This ambiguity mainly manifests itself in four aspects. First, some studies provided a generic definition of participation (i.e., involving end-users in the design process, participants influencing a design project). Second, some do not touch upon the rationale behind selecting a method, and how it enabled participants to influence the design process. Third, some fall short in explaining how the projects made power relations more even. Fourth some do not touch upon the communication process between designers and participants, and among participants. To promote good practices within the PD field [10, 36, 76], we need to work on making the participatory process more transparent about the aforementioned issues. We think that not stating these matters creates a divide between what, in theory, is known to be participatory design and the way it is being practiced. This divide, in the end, makes it difficult to address how or to what extent a project is participatory in the first place.

Besides, there are some issues associated with the understanding that needs to be built among participants and researchers. The latter because the meanings we attach to things can diverge a lot, this diversity can be originated from cultural differences that go beyond ethnicity (e.g., western perspective vs eastern), for example, based in previous undermined experiences, age, professional backgrounds, presence of impairments (i.e., aphasia, autism) or even specific concepts that are used in the particular context of the design process (i.e., interface, usability, mock-up). Thus, when we negotiate meanings of routines, concepts or objects, we can understand each other better, and in so, make communication more even and open. This involves thinking about how the participants can contribute to their skills, experiences, and knowledge. Furthermore, this open communication can help to tailor the methods to the specific needs of the participants and promote higher levels of participation and long-term engagement.

On the other hand, 33 studies in our corpus presented participation of other stakeholders besides the primary group, for example, municipalities [27], clinicians [57], design experts [6], and teachers [40]. Although this seems to be a good practice in terms of extending the scope of participation on a given project, papers usually do not detail the power these stakeholders have in decision making. For instance, the level of influence of a stakeholder participating in framing a project is quite different from those who are involved as participants or consultants during the process. This ambiguity can act in detriment of participant's involvement because it is unclear to what extent stakeholders are deciding for the participants. Thus, an area of further development for PD is to adopt practices that promote the integration of stakeholders as just another participant, instead of involving them in separate activities or stages.

Although we acknowledge the challenge behind addressing these matters in one publication due to writing constraints (e.g., pages limit, presenting the same research in different papers), we believe it is very critical for the development of PD. Otherwise, we can be walking towards a trivialization of PD. To avoid this and inspire future work that supports the values of our community, we need to develop means that promote transparency, open communication and long-term engagement of participants. In that sense, we need to engage in a reflective process of what PD means today and how we are engaging less privileged groups of society in PD projects. We should ask ourselves,

- how the methods (interviews/ workshops/ observations/ toolkits) ensure participant's influence,

- how these methods match the skills and needs of the participants,

- how the design processes are being framed,

- and, how participation influences the design outcome as well as participants' lives.

These questions touch upon different conceptualizations of PD, the participant's roles, stakeholders' roles and the coherence of the selected methods. With the latter, we could use these questions as a framework to design (i.e., plan), implement, and report the participatory process besides evaluating the long-term impact of PD projects. Along with the latter, we can work to facilitate the display of supplementary material related to participatory studies, promoting transparency and open communication. One such alternative could be an open digital space where we can complement the information presented in the papers, for instance, interactive mapping of participatory projects visualizing the diversity of our research such as different areas of work, conceptualizations, roles of participants, in between others. These could even be used as another way for research collaboration that enables us to access real-time data and feedback.

\subsection{Re-framing participants' roles towards higher levels of involvement}

Our analysis illustrated that the researchers' conceptualization of participatory design frames the research process, in line with previous work [36]. Based on our analysis, we identified three conceptualizations of PD: PD as involvement in design activities (n:34), $P D$ as skill development (n:6), and PD as a shared responsibility (n:6), as well as six roles participants can take during the design process: informers, partakers, validators, learners, research partners, and design partners. Using these approaches and roles as an analytical lens, we found that most of the work in our corpus (n: 34) involves participants as informers, partakers or validators, which corresponds with $P D$ as involvement in design activities conceptualization. These roles represent lower levels of influence when compared to the roles of design/research partners, that suggest a more shared perspective of responsibilities during the design process.

We believe that just assuming that participants exercise participation by joining some design activities can result in equating 
attendance to participation, tricking us to promote a passive way of participating. Thus, it is in our best interest as the PD community to promote higher involvement of participants experiencing less privileges (e.g. research partners who can decide how the research is framed) because this can level up their situation either by developing a project or their empowerment and skills. Nevertheless, this is a challenging task.

The first challenge is how to (i.e., through what methods and procedures) ensure a higher level of participant involvement. Analyzing the papers in terms of how they promote higher participation of less privileged participants, we found good practices to overcome this challenge, namely: (1) making a cultural immersion to understand the group of participants before start doing the research [81], (2) include the participants as research partners by sharing the data collection with them [84], and (3) adapt the process to how the participants are doing, thinking, feeling [44]. Reflecting on these practices, it could be beneficial for researchers and practitioners to engage in a "participant immersion" where they can focus on developing a grounded understanding with them and create bonds that will allow the participants to be involved in critical aspects of the design process. The importance of this process is to get to know the participants, understand the barriers, skills, and culture they present. By the latter, researchers could make an informed decision related to which methods and activities to apply, how the responsibilities will be shared with them, how to achieve a more equal involvement. Even though this suggestion can slow the design process as it requires more resources (i.e., time and work) it can help designers and researchers embrace the participants' perspective by experiencing it at the early stages of a PD project.

Another challenge is that promoting higher and sustainable involvement of participants would require more effort from participants. Thus, it is important to think about how we can make the process more engaging for them to maintain their active participation, discover alternative ways of participating or how can we reduce constraints faced by researchers and participants. For example, one could think about a participatory digital platform where people can participate remotely, making it less tiring for them and reducing the time constraints. Alternatively, one could think about the benefits of integrating different technologies (i.e., VR, AI, AR) that might allow us to better understand the needs and experiences of participants. Further, we can work on finding new ways of facilitating the adaption/selection of methods according to the participant's characteristics and differences and, also, new methods to involve the participants in a greater extent, for example in planning and framing, so they reach a "shared responsibilities" type of participation [84].

\subsection{Evaluating the long-term impact of participation}

By choosing participation as a design approach, we have the duty not only of creating and sharing knowledge but to have a positive impact on the life of the participants. Empowerment and improving participant's life quality are values and expected impacts of PD. In this sense, we only found 12 studies that promote the roles of participants as learners (n:6) and design/research partners (n:6), which are directly related to participant's empowerment. The latter represents ethical issues as much as design issues [61, 62]. On the other hand, evaluating long-term impact is difficult as the PD process is usually long and life impact is generally observed years after. Even so, we should at least make a sense of these ethical matters. We should think about how the design outcome is improving the life's quality of the participants and how available the interventions, products or services developed will be for them. And also, we need to think about the skills and knowledge the participants would gain by participating and how will the participants take ownership of the project and maintain it in time. Maintaining the empowerment after the project finishes is key to have a real impact on the group of participants after the designers leave the intervention [10, 34]. By PD, we cannot solve all the difficulties that people in less privileged situations face, but we surely do not seek to worsen their situation by developing products they will not be able to access, or by creating projects that will not be sustained in time. In that sense, we should work on developing methods that promote ownership and sustainability of the projects developed, and, advance participant's skills.

\subsection{Limitations}

One limitation of our work is that the results refer only to participatory design with participants that have more barriers to participation, so they cannot be generalized to other communities and research in PD. Another limitation is that we can only be informed by what researchers presented in their papers. Thus, aspects not displayed in the studies we cannot asses. For example, we do not have complementary information on the details of each project (or projects in general) or their impact assessments, (i.e., how they give back to the community). Also, we need to note that, our study started by considering less privileged participants as part of a community of "often-unprivileged" [24, 25]people. By conducting our analysis, we understood that there were many different kinds of participants and that, just because they presented a similar need (i.e. using prosthetics leg, mental health), it did not necessarily meant they form a community. At that point, our research focused more on the characteristics of the participants more than trying to group them.

\section{CONCLUSION}

To date, various issues and challenges have been raised around the practices of $\mathrm{PD}$ concerning what we understand for participation [41], how participation has been practiced [10, 21, 45], and, when, where and how participants get to influence a project [36, 59]. Areas that have been pointed out as blurry in the last years, and even more when we work with participants with less privileges [54, 61, 62]. Participation benefits people in different ways, either by promoting new designs that will contribute to their life, by developing skills and empowerment or by creating knowledge. With this study, we explored how participation has been developed in practice when participants are individuals who have experienced less privileges. While conducting this study, we have learned that participation, in this context, is not so much about a specific method but the confluence of different interventions promoting the influence of participants in a project. In this sense, we think that there is no "participatory method" per se, but different ways of enabling people 
to get engaged in the development of projects that seek to improve their life.

We found that, the way the process is carried on changes in regard of researchers' conceptualization of PD (i.e. PD as involvement in design activities, as skill development or as shared responsibility), their understanding of the participants (e.g., skills, challenges, previous experiences), which simultaneously frames the role they will have during the participatory process (i.e. participants as informants, partakers, validators, learners, research partner or design partner). Along with the latter, we found different challenges and good practices faced by researchers and participants during the participatory process (i.e., understanding, leveraging and maintaining participation in the long term).

Finally, we have discussed different topics we need to further develop and agree upon, to maintain the values and meaning of participatory design. These matters have been relevant in the past, they are relevant today and, with this research, we think they will be still relevant in the future. There is work to be done around how to rise less-privileged participants' participation in projects, how to promote their skills developments, instead of promoting fixed methods and ready-made recipes for participatory design, and how to develop new sustainable ways of sharing responsibilities with participants.

\section{REFERENCES}

[1] Almohamed, A. and Vyas, D. 2016. Vulnerability of displacement: challenges for integrating refugees and asylum seekers in host communities. Proceedings of the 28th Australian Conference on Computer-Human Interaction (2016), 125-134.

[2] Amatullo, M. 2013. The Teen Art Park Project: Participatory Design Tools For Envisioning Public Spaces For Artistic Expression. DESIS. (2013), 116.

[3] B. Gaver, T. Dunne, E.P. 1999. Design: Cultural Probes. Magazine Interactions. Volume 6 I, 1 (1999), 21-29. DOI:https://doi.org/10.1145/291224.291235.

[4] Baskerville, R.L. and Myers, M.D. 2015. Design ethnography in information systems. Information Systems fournal. 25, 1 (2015), 23-46.

[5] Binder, T. et al. 2019. Participation in Design Things. Design Things. (2019), 92-101. DOI:https://doi.org/10.7551/mitpress/8262.003.0011.

[6] Birch, J. et al. 2017. Creativity, play and transgression: children transforming spatial design. CoDesign. 13, 4 (2017), 245-260.

[7] Bjögvinsson, E. et al. 2012. Design things and design thinking: Contemporary participatory design challenges. Design issues. 28, 3 (2012), 101-116.

[8] Blake, V. et al. 2016. Using participatory design to engage young people in the development of a new online tool to increase help-seeking. Fournal of Applied Youth Studies. 1, 3 (2016), 68.

[9] Bødker, K. et al. 2009. Participatory IT design: designing for business and workplace realities. MIT press.

[10] Bødker, S. 1996. Creating conditions for participation: conflicts and resources in systems development. Human-computer interaction. 11, 3 (1996), 215-236.

[11] Branco, R.M. et al. 2016. Playing with personalisation and openness in a codesign project involving people with dementia. Proceedings of the 14th Participatory Design Conference: Full papers-Volume 1 (2016), 61-70.

[12] Brandt, E. et al. 2012. Ways to engage telling, making and enacting. Routledge International Handbook of Participatory Design. (2012), 145-181.

[13] Bratteteig, T. and Wagner, I. 2016. Unpacking the Notion of Participation in Participatory Design. Computer Supported Cooperative Work: CSCW: An International fournal. 25, 6 (2016), 425-475. DOI:https://doi.org/10.1007/s10606-016-9259-4.

[14] Braun, V. and Clarke, V. 2006. Using thematic analysis in psychology. Qualitative research in psychology. 3, 2 (2006), 77-101.

[15] Brown, A. V and Choi, J.H. 2018. Refugee and the post-trauma journeys in the fuzzy front end of co-creative practices. Proceedings of the 15th Participatory Design Conference: Full Papers-Volume 1 (2018), 15.

[16] Buchmüller, S. et al. 2011. Bridging the gender and generation gap by ICT applying a participatory design process. Personal and Ubiquitous Computing. 15, 7 (2011), 743-758.

[17] Cabrero, D.G. et al. 2016. A hermeneutic inquiry into user-created personas in different Namibian locales. Proceedings of the 14th Participatory Design Conference Full papers-Volume 1 (2016), 101-110.

[18] Carroll, J.M. and Rosson, M.B. 2007. Participatory design in community informatics. Design studies. 28, 3 (2007), 243-261.

[19] Clement, A. and den Besselaar, P. 1993. A retrospective look at PD projects. Communications of the ACM. 36, 6 (1993), 29-37.
[20] community | Cambridge Dictionary: 2020. https://dictionary.cambridge.org/ dictionary/english/community. Accessed: 2020-03-03.

[21] Costantino, T. 2014. Issues of Participation: A Framework for Choices and Compromises. International fournal of Sociotechnology and Knowledge Development (IJSKD). 6, 4 (2014), 41-61.

[22] Dabaieh, M. and Alwall, J. 2018. Building now and building back. Refugees at the centre of an occupant driven design and construction process. Sustainable cities and society. 37, (2018), 619-627.

[23] Dearden, A. and Rizvi, H. 2008. Participatory IT design and participatory development: a comparative review. Proceedings of the Tenth Anniversary Conference on Participatory Design 2008 (2008), 81-91.

[24] Department of Economic and Social Affairs ST/ESA/362 United Nations 2016. Leaving no one behind: the imperative of inclusive development. Report on the World Social Situation 2016.

[25] Department of Economic and Social Affairs ST/ESA/366 United Nations 2018. Promoting Inclusion through Social Protection Report on the World Social Situation 2018 Division for Inclusive Social Development.

[26] Derr, V. 2015. Integrating community engagement and children's voices into design and planning education. CoDesign. 11, 2 (2015), 119-133.

[27] Dindler, C. and Iversen, O.S. 2014. Relational expertise in participatory design. Proceedings of the 13th Participatory Design Conference: Research Papers-Volume 1 (2014), 41-50.

[28] DiSalvo, C. et al. 2012. Communities: Participatory Design for, with and by communities. Routledge International Handbook of Participatory Design. Routledge. 202-230.

[29] Duarte, A.M.B. et al. 2018. Participatory design and participatory research: an HCI case study with young forced migrants. ACM Transactions on Computer-Human Interaction (TOCHI). 25, 1 (2018), 3.

[30] Fassi, D. and Sedini, C. 2017. Design actions with resilient local communities: Goals, drivers and tools. Strategic Design Research fournal. 10, 1 (2017), 36-46.

[31] Frauenberger, C. et al. 2011. Designing technology for children with special needs: bridging perspectives through participatory design. CoDesign. 7, 1 (2011), 1-28.

[32] Fredrikson, M. et al. 2011. Building a Community of Musical Practice for Children in a Child-centered Way-JamMo Singing Game for 3-6 Aged Children. Proceedings of the NBE 2011. (2011), 39.

[33] Galliers, J. et al. 2012. Words are not enough: empowering people with aphasia in the design process. Proceedings of the 12th participatory design conference: Research papers-volume 1 (2012), 51-60.

[34] Gärtner, J. and Wagner, I. 1996. Mapping actors and agendas: political frameworks of systems design and participation. Human-Computer Interaction. 11, 3 (1996), $187-214$.

[35] Gudowsky, N. et al. 2017. Transdisciplinary forward-looking agenda setting for age-friendly, human centered cities. Futures. 90, (2017), 16-30.

[36] Halskov, K. and Hansen, N.B. 2015. The diversity of participatory design research practice at PDC 2002-2012. International fournal of Human Computer Studies. 74, (2015), 81-92. DOI:https://doi.org/10.1016/j.ijhcs.2014.09.003.

[37] Hornung, D. et al. 2017. Navigating relationships and boundaries: Concerns around ict-uptake for elderly people. Proceedings of the 2017 CHI Conference on Human Factors in Computing Systems (2017), 7057-7069.

[38] Hussain, S. 2010. Empowering marginalised children in developing countries through participatory design processes. CoDesign. 6, 2 (2010), 99-117.

[39] Hussain, S. and Sanders, E.B.-N. 2012. Fusion of horizons: Co-designing with Cambodian children who have prosthetic legs, using generative design tools. CoDesign. 8, 1 (2012), 43-79.

[40] Iivari, N. and Kinnula, M. 2018. Empowering children through design and making: towards protagonist role adoption. Proceedings of the 15th Participatory Design Conference: Full Papers-Volume 1 (2018), 16.

[41] Iversen, O.S. et al. 2012. Participation and HCI: Why Involve People in Design? Proceedings of Chi, 5.-10. May, Austin, Tx, Usa. (2012).

[42] Kanstrup, A.M. 2012. A small matter of design: an analysis of end users as designers. Proceedings of the 12th Participatory Design Conference: Research PapersVolume 1 (2012), 109-118.

[43] Kanstrup, A.M. et al. 2014. Design with the feet: walking methods and participatory design. Proceedings of the 13th Participatory Design Conference: Research Papers-Volume 1 (2014), 51-60.

[44] Kanstrup, A.M. and Bertelsen, P. 2016. Bringing New Voices to Design of Exercise Technology: participatory design with vulnerable young adults. Proceedings of the 14th Participatory Design Conference: Full papers-Volume 1 (2016), 121-130.

[45] Kensing, F. and Blomberg, J. 1998. Participatory design: Issues and concerns. Computer Supported Cooperative Work (CSCW). 7, 3-4 (1998), 167-185.

[46] Kinnula, M. et al. 2017. Cooperation, Combat, or Competence Building-What Do We Mean When We Are 'Empowering Children'in and through Digital Technology Design? (2017).

[47] Kraff, H. 2018. A tool for reflection-on participant diversity and changeability over time in participatory design. CoDesign. 14, 1 (2018), 60-73.

[48] Leong, T.W. and Robertson, T. 2016. Voicing values: laying foundations for ageing people to participate in design. Proceedings of the 14th Participatory Design 
Conference: Full papers-Volume 1 (2016), 31-40.

[49] Lindsay, S. et al. 2012. Engaging older people using participatory design. Proceedings of the SIGCHI conference on human factors in computing systems (2012), 1199-1208.

[50] Luck, R. 2003. Dialogue in participatory design. Design studies. 24, 6 (2003), $523-$ 535

[51] Madden, D. et al. 2014. Probes and prototypes: a participatory action research approach to codesign. CoDesign. 10, 1 (2014), 31-45.

[52] Makhaeva, J. et al. 2016. Creating creative spaces for co-designing with autistic children - The concept of a "Handlungsspielraum." ACM International Conference Proceeding Series. 1, (2016), 51-60. DOI:https://doi.org/10.1145/2940299.2940306.

[53] Merkel, C.B. et al. 2005. Sustaining computer use and learning in community computing contexts: Making technology part of who they are and what they do. The fournal of Community Informatics. 1, 2 (2005).

[54] Merritt, S. and Stolterman, E. 2012. Cultural hybridity in participatory design. Proceedings of the 12th Participatory Design Conference: Exploratory Papers, Workshop Descriptions, Industry Cases-Volume 2 (2012), 73-76.

[55] Moutafidou, A. and Bratitsis, T. 2018. Digital Storytelling: Giving Voice to Socially Excluded People in Various Contexts. Proceedings of the 8th International Conference on Software Development and Technologies for Enhancing Accessibility and Fighting Info-exclusion (New York, NY, USA, 2018), 219-226.

[56] Muller, M.J. 2009. Participatory design: the third space in HCI. Human-computer interaction. CRC press. 181-202.

[57] Orlowski, S. et al. 2019. Designing for practice: understanding technology use in rural community-based youth mental health contexts. CoDesign. 15, 2 (2019), 163-184.

[58] Parsons, S. and Cobb, S. 2013. Who chooses what I need? Child voice and userinvolvement in the development of learning technologies for children with autism. EPSRC Observatory for Responsible Innovation in ICT. (2013).

[59] Puri, S.K. et al. 2004. Contextuality of Participation in IS Design: A Developing Country Perspective. Proceedings of the Eighth Conference on Participatory Design: Artful Integration: Interweaving Media, Materials and Practices - Volume 1 (New York, NY, USA, 2004), 42-52.

[60] Redström, J. 2008. RE: Definitions of use. Design studies. 29, 4 (2008), 410-423.

[61] Robertson, T. and Simonsen, J. 2012. Challenges and opportunities in contemporary participatory design. Design Issues. 28, 3 (2012), 3-9.

[62] Robertson, T. and Wagner, I. 2012. Ethics: Engagement, representation and politics-in-action. Routledge international handbook of participatory design. Routledge. 84-105.

[63] Rönkkö, K. et al. 2004. Personas is not applicable: local remedies interpreted in a wider context. Proceedings of the eighth conference on Participatory design: Artful integration: interweaving media, materials and practices-Volume 1 (2004), 112-120.

[64] Roper, T. et al. 2019. Collaborative virtual environment to facilitate game design evaluation with children with ASC. International fournal of Human-Computer Interaction. 35, 8 (2019), 692-705.

[65] Sabiescu, A.G. and Memarovic, N. 2013. Participatory Design for Cultural Representation: a cultural transparency perspective. IFIP Conference on HumanComputer Interaction (2013), 611-618.

[66] Sandercock, L. and Attili, G. 2010. Digital ethnography as planning praxis: An experiment with film as social research, community engagement and policy dialogue. Planning Theory \& Practice. 11, 1 (2010), 23-45.

[67] Sanders, E.-N. 2000. Generative tools for co-designing. Collaborative design. Springer. $3-12$.

[68] Sanoff, H. 2011. Multiple Views of Participatory Design. Focus. 8, 1 (2011), 131-143. DOI:https://doi.org/10.15368/focus.2011v8n1.1.

[69] Ssozi-Mugarura, F. et al. 2016. Supporting community needs for rural water management through community-based co-design. Proceedings of the 14th Participatory Design Conference: Full papers-Volume 1 (2016), 91-100.

[70] St John, N. Towards more culturally inclusive communication design practices: exploring creative participation between non-Indigenous and Indigenous people in Australia.

[71] Stappers, P.J. and Sanders, E.B.-N. 2004. Generative Tools for Context Mapping: Tuning the Tools. Design and Emotion. (2004), 85-89. DOI:https://doi.org/10.1201/ 9780203608173-c14.

[72] Stollmann, J. 2016. Neighbourhood resilience in mass housing: co-production via research-by-design. Building Research \& Information. 44, 7 (2016), 737-753.

[73] Suerdem, A. and Oztaysi, B. 2015. Interdisciplinary collaboration of engineers and social researchers to face societal challenges: designing an e-recruitment system for disadvantaged groups. Procedia-Social and Behavioral Sciences. 195, (2015), 2566-2575.

[74] Thomas, R. et al. 1988. Taking charge, how communities are planning their futures. International City Management Association.

[75] Vines, J. et al. 2012. Cheque mates: participatory design of digital payments with eighty somethings. Proceedings of the SIGCHI Conference on Human Factors in Computing Systems (2012), 1189-1198.

[76] Vines, J. et al. 2013. Configuring participation: on how we involve people in design. Proceedings of the SIGCHI Conference on Human Factors in Computing Systems (2013), 429-438.

[77] Wadley, G. et al. 2013. Participatory design of an online therapy for youth mental health. Proceedings of the 25th Australian Computer-Human Interaction Conference: Augmentation, Application, Innovation, Collaboration (2013), 517-526.

[78] Wallace, J. et al. 2013. Making design probes work. Proceedings of the SIGCHI Conference on Human Factors in Computing Systems - CHI '13. (2013), 3441. DOI:https://doi.org/10.1145/2470654.2466473.

[79] Walsh, G. et al. 2013. Octoract: an eight-dimensional framework for intergenerational participatory design techniques. CHI'13 (2013).

[80] Wang, W. et al. 2019. On the role of in-situ making and evaluation in designing across cultures. CoDesign. (2019), 1-18.

[81] Winschiers-Theophilus, H. et al. 2012. Altering participation through interactions and reflections in design. CoDesign. 8, 2-3 (2012), 163-182.

[82] Winschiers-Theophilus, H. et al. 2010. Being participated: a community approach. Proceedings of the 11th Biennial Participatory Design Conference (2010), 1-10.

[83] Xu, D.Y. and Read, J.C. 2012. Experience Focused Requirements Gathering with Children and Young People-Balancing Player, Learner and User (PLU) Requirement Needs. Usability-and Accessibility-Focused Requirements Engineering. Springer. 62-76.

[84] Xu, Y. and Maitland, C. 2019. Participatory data collection and management in low-resource contexts: a field trial with urban refugees. Proceedings of the Tenth International Conference on Information and Communication Technologies and Development (2019), 18. 